Vol. 3, No. 3, September 2021, pp. 321-329, doi.org:10.52567/pjsr.v3i3.254

www.pjsr.com.pk

\title{
A SOCIOLOGICAL ANALYSIS OF THE IMPACT OF MODERN MEDIA ON FAMILY FUNCTIONS IN PUNJAB, PAKISTAN
}

\author{
Ghulam Ghaus \\ Ph.D. Scholar, Department of Rural Sociology, \\ University of Agriculture Faisalabad \\ uafghaus@gmail.com \\ Ashfaq Ahmad Maan \\ Professor (Rtd.), Department of Rural Sociology, \\ University of Agriculture, Faisalabad \\ ashfaqmaan@gmail.com \\ Izhar Ahmad Khan \\ Associate Professor, Department of Rural Sociology, \\ University of Agriculture, Faisalabad \\ izharkhan99@uaf.edu.pk
}

\begin{abstract}
The family is a particularly an important institution and the basic building block of any society, which performs the important functions of socializing the young and meet the emotional needs of their members. A stable family supports the social order and economic stability. Over the time, series of changes have been introduced in the functions of the family. Many internal and external forces have taken action against the family, producing a fundamental change in family functions. Therefore, the current study helps to evaluate the effects of modern media on family function in the Punjab, Pakistan. This research is based on a quantitative methodology. A sample of 672 respondents was selected from three selected districts namely Sheikhupura, Chakwal and Khanewal of Punjab province. Multistage sampling technique was used for data collection. The data was collected with the help of a well-structured interview schedule. The findings obtained from collected data revealed that modern media has negative effects for family functions by decreasing the intensity and duration of interaction among family members. Modern media has also affected family gatherings, and play a vital role in breaking old family traditions and change the socializing patterns, norms and values of society.
\end{abstract}

Keywords: Modern media, Family functions, Implication, Social isolation, Socialization.

\section{INTRODUCTION}

It is clear that modern media has become an inextricable component of human life, and that it has a significant impact on family functions. A small percentage of the population used modern media in 2005, but by 2019, this number has grown up to 79 percent. With 2.38 billion monthly active users, Facebook remains the most popular website in the world, although Instagram (1 billion), We Chat (1 billion), and Twitter (330 million) has significant followings (Ortiz-Ospina, 2019).

Previous researches have shown that modern media has a negative impact on children's attitudes and behavior. As "the death of childhood," destroy their individuality and innocence. The current research focuses on how modern media has changed and altered family functions. It examines the existing literature of how modern media affect family gatherings, limits outdoor recreational activities among family members to date, and examines the impact of modern media on the socialization process and traditional family functions (Jenkins et al., 2020).

It is estimated that more than 17.2 million social media users in Pakistan have their accounts on Facebook. Twitter is also becoming a popular social media platform with more than 2.80 million users per day. Despite having a high illiteracy rate and rural population, the tendency of Pakistan towards these social media platforms and increasing number of users is surprising (Zulfi, 2016).

Print media is known as the fundamental means of communication that can be read on a piece of 
paper. The most common forms of print media include books, newspapers, magazines, newsletters, brochures, posters, and press releases. The internet's popularity as a mass media stems from the fact that it allows a person to virtually access any type of information by just pressing a button (Ahmad, 2016).

Modern media technologies have caused a significant transition in society's social structure, implying that individuals, households, and families have to adapt in a variety of ways. The modern media technology has the most powerful impact on interaction and communication between individuals in the household and family members (Church et al., 2010).

Every aspect of family life has been affected by technology. Most of the time of people has spent on indoors as compared to the outside of the house. The time spent on modern media technologies such as watching television or using a computer is approximately on average eight hours a day. With all the modern media technologies that have been existing nowadays, nobody wants to get out of the home anymore. In present time, everything revolves around modern technology. Most of the children after coming back from school usually go to use a computer or watch TV. People have become habitual of these technologies and they would just laze about doing nothing except using modern technology. Most of them would not interact and chat with other family members even in the absence of these technologies due to power cut (Moradi, 2016).

Research on family and technology concludes that the time spent on online activities decrease the quantity of time spent by family together, because quantity of time that is spent online is related to diminished feelings of family intimacy. One possible cause is use of the internet at home which might be linked to diminished family ties. The children spending more time on the internet are liable to create conflict in the house. This conflict over use of the internet in the home disturbs the functions of family (Taft, 2015).

Television, computers and games have negative impacts on youngsters. These technologies lead them towards social isolation. Their social intellectual imagination and linguistic development are at risk due to increased social isolation. Moreover, as children are spending increased time at indoors, their wellbeing is under threat, and they are at risk of obesity as well. It reduced the opportunities for interactions within the household that is essential for their emotional development and socialization. In other words, modern media technologies are affecting social interaction among individuals and members of the family within a household in a negative way (Plowman et al., 2010).

It is observed that youth aged 8-18 years consume more than 7 hours daily on entertainment media. The people involved with a digital screen, do not do exercise, don't meet up with friends, nor spend quality time with family members and with other relationships. Other effects of massive use of modern media are increasing rate of obesity, and because of their mental absence while giving the company to other people, they were unable to manage hurdles in the maintenance and development of the relationship (Cloninger \& Strembicki, 2013).

\section{SIGNIFICANCE OF THE STUDY}

Society generally believes that the family is a natural and basic institution that is responsible for social and emotional security of its members. From a variety of fields and perspectives, research on family institution has always attracted researchers and scholars. Sometimes even a strong interest in family research of people can be attributed to the deep connection between society and everyday life. The present study is designed to explore the implications of modern media for family functions. These technologies are used not only for communication and entertainment but also to change the family structure and its functions. Intimacy and closeness between family members is changed in the modern family. This research focused on exploring the ways by which modern media is playing an integral role in the everyday lives of families in the modern age. The main objective of this study is to explore the extent of modern media on various family functions.

\section{REVIEW OF LITERATURE}

Mesch (2003) pointed out that the level of attachment and utilization of the internet by a person is positively associated with his low-quality relationship with family. The core cause of intimacy between parents and children is based upon the characteristics of intimacy and the intensity of interaction. He concluded that this negative relationship was not due to the frequent utilization of technology-related 
devices, but another variable was involved. That variable was the type of activity performed online by users. After three years, he critically evaluated that the high frequency of internet utilization by teenagers reduces family interaction time and increases family conflict. Modern media has negative effects on the family institution. The family member's cooperation is also in decline.

Buckingham (2000) reported that with the maximum use of modern media, the households are suffering from isolation, and individualized behavior is developed rather than collective behavior. The conclusion of this study highlights that modern media is minimizing the chances of direct interaction among the family members.

Ray and Spencer (2004) pointed out that relationship among family members has drastically changed. The sentiments of solidarity association with kin and other members are relatively becoming weak. Although it might be a sense of accountability present among family members due to the massive use of modern media, the association among family members and time spending together have reduced. There is a huge communication gap and increased sentiments of individualism within house.

Plowman et. al. (2008) believed that the majority number of children in the UK at the age of three and four growing up with families are equipped with the technology. They also explored the number of children who have direct access to the television; the percentage of those children is 75 percent. Moreover, 98 percent of children are living with family having a cellphone. A vast number of children can handle games, laptops and tabs. Furthermore, several children were enjoying leisure time with DVD players, cameras, and $\mathrm{mp} 3$ players. This culture is responsible to change the family functions.

William and Merten (2011) investigated the use of multiple media technologies for young people and their parents to investigate the effect of these techniques on family connectivity among parent and child relational change. Thus, parents consider information and communication technologies to facilitate the family's communication quality and proximity. But on the other hand, they also agreed with the notion that excessive usage of devices have reduced family interpersonal relationship, and caused increased level of isolation and alienation among people living in the same building. On the other hand, a large number of technical devices and a high frequency of their use appear to be related to family member's proximity and cohesion, leading to the isolation of people living in the same house.

Shahzad et. al. (2015) summarized the effects of modern media on types of families and their characteristics in Ghana. Most traditional families are converting into nuclear families. No doubt, changing family structure has great impact on family functions. Some positive effects of modern media, he described as when teenage add their parents as a friend on face book and don't' hide their contacts from them and discuss their inner feelings with them, it can be proved as a great source of dispute resolution between both of parties. It was studied that having friendship on Facebook, Twitter and other social media applications, there exists a positive relationship between this act and increase intimacy among children regarding their parents. On the other hand, while discussing time as a variable, he concluded that adding their family members on Facebook may increase family time, but it can diminish the true feeling of family.

Beavers and Hampson (2017) pointed out that it has been proved by multiple types of research that digital media is the most important tool in changing family dynamics. It forms a new scenario of interaction and reorganizes the pattern of the relationship. They concluded that government should launch some educational projects for the community before the digitalization of society, particularly regarding family. It would be helpful for families to digitalize themselves in the most natural and normal way.

\section{THEORETICAL FRAMEWORK}

A theoretical framework consists of the phenomena to explain the hypothetical thoughts and the statements that can be verified with their interrelation. Reviews that are related to a particular issue give awareness about the facts and provide it to the researcher to understand the problem in a better way. But on the other hand, the theory is based on a systematic observation of laws and facts concerned with a specific area of an issue (Babbie, 2010).

The theory provides an association between research and problems, which is under investigation in a study. In the task of streamlining the facts, theory facilitates the researcher. It is a set of interconnected rational concepts that go for the explanation of some phenomena or group of observable facts (Sternberg, 2001). Theoretical models used in the present study are as under: 


\section{McMaster Family Functioning Mode Theory}

The working model theory of the McMaster family was proposed at the end of the $20^{\text {th }}$ century. It involves the family system as the core process and accepts that the basic functions of the family are to provide satisfactory environmental conditions for the development of family members at the physical, psychological, social, and other levels. To achieve the basic functions, the home system must complete a series of tasks, including the basic tasks of providing food and clothing, development tasks, (how to adapt and promote member growth and development), and disaster tasks (How to deal with all types of family emergencies). The family system promotes sustainability in society by completing a series of family tasks/ functions.

In the McMaster model of family functions, the family is considered open dynamic system that is more than the characteristics of the individuals or dyadic interactions. A strong, healthy family system possesses strengths across several domains including the positive perception of the future, cohesion, communication, emotional expression, setting clear roles and boundaries and problem solving (Alderfer et al., 2008).

The theory divides families into six types: the ability of the family to perform basic functions and the ability to perform basic tasks. To maintain effective family functions, the family performs necessary functional capabilities. Communication information exchange between family members can be directly understood at any time. The role of the family refers to the behavioral patterns established by family members to complete the family function. Emotional response refers to the degree of the emotional response of family members to behavioral stimuli. Emotional participation refers to the level of attention and attention of family members to family activities and other things. Behavioral control refers to the different behavioral control modes in different situations.

Also, the McMaster Model of family functions defines six facets of family experiences and relationships that are critical in determining and evaluating the family system's level of functions. Communication, problem solving, tasks, affective responsiveness, affective engagement, and behavior management are among the six fields. Each of these six areas is linked to the family's overall functions as well as the functioning of individual family members (Miller et al., 2000).

\section{Modern Media Technologies and Spillover}

Some decade's earlier, the usage of modern media technologies and its implications was not a buzz word regarding work and home. But nowadays, mostly studies are enrich with the content that discovers the contribution of communication and information technology in these both boundaries. Berkowsky (2013), tried to discover these implications by using the boundary theory to dig out the blurred areas of these two domains due to excessive usage of modern media in this modern age. He concluded that multiple spillover effects are being observed due to excessive usage of modern media technologies. These technologies have reduced the distinction between these two domains of the life. People are doing job from home and homes are being managed as work place, which have reduced the family functions and family integration, and created many loop holes in both domains of the life. He also pointed out some series of conflicts emerging in family life due to these spillover effects of media technologies. These technologies are creating parental issues with their children regarding the time and duration of using these technologies at home (Stevenson, 2011).

\section{Rationale of Theories}

These theories of understanding social phenomena are the tradition of social science. Although the family is the basic institution of society, its functions are very natural and important to any society and its members, but the society that adjusts and adapts with changing things can operate according to the hours required. All these theories mentioned above emphasized family functions, and suitable division of labor or family rule to cope with our culture.

\section{MATERIALS AND METHODS}

Methodological techniques are very important for empirically analyzing sociological problems. Sound methodology is vitally important to establish a chain of knowledge and empirical verification of 
hypothesis. The purpose of this research is to explain various tools to be employed for conducting the study. The scientific methodology is a system of explicit rules and procedures upon which research is based and against which claims for knowledge are evaluated (Nachmias \& Nachmias, 1996).

Methodology refers to more than a simple set of methods, it refers to rational and philosophical assumptions that underline a particular study. This is why, scholarly literature includes a section on the methodology of the research (Creswell, 2003).

The study is mainly based on primary sources of information. Extensive fieldwork was carried out for the collection of data through a well-structured interview schedule which includes close ended questions on different aspects regarding the implications of modern media for family functions. This research is based on quantitative methodology. A sample of 672 respondents was selected from three selected districts of Punjab province by using multistage sampling technique.

A large population is divided into small proportions to make the process of sampling more practical in multistage sampling. It is a combination of cluster sampling and simple random sampling techniques (McBurney \& White, 2012). The detail of sampling procedure is presented in sampling layout.

\section{Sampling Layout}

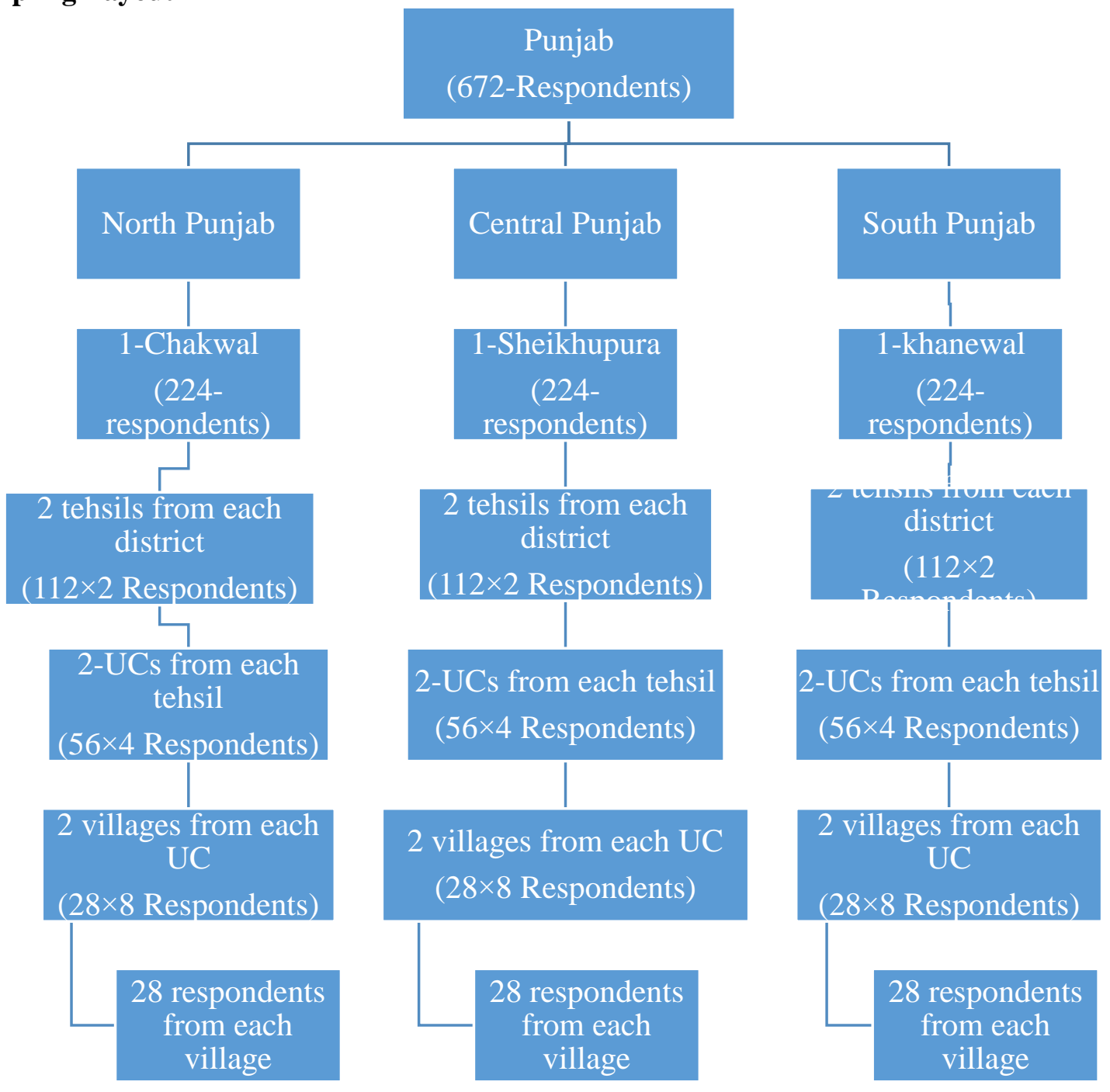

\section{RESULTS AND DISCUSSIONS}

The essential and main portion of the research work is the analysis and discussion of the data collected by the researcher, including its explanation. Generalization and implementation of previous researches was unable to provide reliable social world predictions, which is the main objective of current research. 
Table 1: Distribution of the respondents according to their sex

\begin{tabular}{|l|l|l|}
\hline Sex & Frequency & Percent \\
\hline Male & 370 & 55.1 \\
\hline Female & 302 & 44.9 \\
\hline Total & 672 & 100.0 \\
\hline
\end{tabular}

Table 1 contains the distribution of the gender of the respondents. $55.1 \%$ of the respondents were male, while $44.9 \%$ of the respondents were female in the sample. However, research suggests that male and female users of modern media are influenced differently (Jenkins et al., 2020).

Table 2: Distribution of the respondents according to use of modern media

\begin{tabular}{|l|l|l|}
\hline Using modern media & Frequency & Percent \\
\hline Yes & 621 & 92.4 \\
\hline No & 51 & 7.6 \\
\hline Total & 672 & 100 \\
\hline
\end{tabular}

The table 2 indicates that $92.4 \%$ of the respondents were users of modern media, and only $7.6 \%$ of the respondents were not the users of modern media. Consuming more time on the modern media leads to decrease interaction duration among family members. Duration of interaction among family members automatically decreases when they consume more time on television watching, video games playing, music listening etc. Rather than socialization, playing, or going outside for some recreation together, they get busy using digital communication devices.

Table 3: Distribution of the respondents according the daily spending of time on modern media

\begin{tabular}{|c|c|c|}
\hline $\begin{array}{c}\text { How many hours do you use } \\
\text { per day? }\end{array}$ & Frequency & Percent \\
\hline 1 to 3hours & 421 & 62.6 \\
\hline 3 to 5hour & 133 & 19.8 \\
\hline 7 to above & 118 & 17.6 \\
\hline Total & 672 & 100 \\
\hline
\end{tabular}

Table 3 depicts that $62.6 \%$ of the respondents were spending 1 to 3 hours on modern media; (19.8) percent of the respondents were spending 3 to 5 hours on modern media daily; $17.6 \%$ of the respondents remained busy for more than 7 hours on modern media. It is observed that youth aged 8-18 years consume more than 7 hours daily on modern media. Television, computers and games have negative impacts on youngsters. These technologies lead them towards social isolation. It reduced the opportunities for interactions within the household that is essential for their emotional development and socialization (Cloninger \& Strembicki, 2013).

The table 4 shows the calculated average of the response about the implications of modern media for family functions. There are different questions asked by the researcher. The first question was "Do you think that the use of modern media affects family functions. Most of the respondents with a mean of (3.42) and SD of (1.02) were agreed with this option. Similarly, the second question was Do you think that the particular socialization function of the family is affected by the modern media? The majority of the respondents with a mean of (3.43) or SD of (1.20) were agreed. 
Table 4: Mean, standard deviation and perception of respondents regarding the implication of modern media

\begin{tabular}{|l|c|c|c|}
\hline \multicolumn{1}{|c|}{ Implications of modern media for family functions } & Mean & S. D & Perception \\
\hline Do you think that the use of modern media affects family functions? & 3.42 & 1.02 & Agree \\
\hline $\begin{array}{l}\text { Do you think that the particular socialization function of the family is } \\
\text { affected by modern media? }\end{array}$ & 3.43 & 1.20 & Agree \\
\hline $\begin{array}{l}\text { Do you think that you are spending ample time with your family } \\
\text { members? }\end{array}$ & 3.76 & 1.07 & Agree \\
\hline $\begin{array}{l}\text { Do your parents support you to use modern media? } \\
\text { Do you think that modern media is affecting family interactions? }\end{array}$ & 3.78 & 1.04 & Neutral \\
\hline $\begin{array}{l}\text { Do you think modern media affect your participation in family } \\
\text { bonding? }\end{array}$ & 3.27 & 1.07 & Neutral \\
\hline $\begin{array}{l}\text { Do you think your parents have the same attitude towards male and } \\
\text { female members regarding use of modern media? }\end{array}$ & 3.36 & 1.26 & Neutral \\
\hline $\begin{array}{l}\text { Do you agree that modern media affect the outdoor recreational } \\
\text { activities of families? }\end{array}$ & 3.62 & 1.29 & Agree \\
\hline $\begin{array}{l}\text { Do you agree that the use of more networking sites is decreasing the } \\
\text { frequency of communication among family members? }\end{array}$ & 3.86 & 0.98 & Agree \\
\hline Do you agree about the advantages of modern media? & 3.27 & 1.07 & Neutral \\
\hline Do you think that the non-users of modern media feel embracement? & 3.84 & 1.14 & Agree \\
\hline $\begin{array}{l}\text { Do you think modern media advancement makes life easier by } \\
\text { connecting you with all persons of the world? }\end{array}$ & 3.24 & 1.26 & Neutral \\
\hline $\begin{array}{l}\text { Do you think modern media play important role in breaking traditional } \\
\text { barriers? }\end{array}$ & 4.21 & 1.03 & $\begin{array}{c}\text { Strongly } \\
\text { agree }\end{array}$ \\
\hline $\begin{array}{l}\text { Do you agree modern media has changed the norms, values morals, } \\
\text { beliefs, and ideals of society? }\end{array}$ & 3.58 & 1.10 & Agree \\
\hline
\end{tabular}
1. Strongly Disagree $(1.00-1.80)$
2. Disagree (1.81-2.60) 3. Neutral (2.61- 3.40)
4. Agree. $(3.41-4.20)$
5. Strongly Agree (4.21- 5.00)

Youngsters pay no attention to their parents and do not listen to them when they tell them to limit their usage of modern media. Socialization of children is an important function of the family, but modern media is deluding this function as children don't pay any heed to their parents' advice. When asked about that if they think that they are spending ample time with their family members? Majority of respondents remained agreed with the mean of (3.7) and SD of (1.07). The next question was if your parents support you to use modern media? The response revealed that mean was (2.78) and SD (1.04) and Perceptions were neutral. When researcher was asked do you think that modern media is the opposite regarding family functions. It was seen that mean of (3.44) and SD of (1.06), and Perception were agreed.

The respondent's perceptions were neutral for the question of do you think modern media affect your participation in family bonding; percentage of mean was (3.27) and SD (1.26). Today's modern media has become a permanent part of our lives which has significantly decreased communication among family members as well destroyed family cultures and the joy of family gatherings. A question whether you agree your parents has the same attitude towards male and female members regarding use of modern media. The majority of respondents were replied with a neutral perception to a mean of (3.36) or SD (1.26). To a question that is modern media effecting the outdoor recreational activities of families; the majority of the respondents were agreed with mean (3.62) and SD (1.29). 
The next question was about the use of more social networking sites decreasing the frequency of communication among family members. The response shows that mean (3.86) or SD (0.98) and perception were agreed. To another question about the advantages of modern media, the majority of the respondents had a perception about this statement with neutral mean of (3.27) and SD (1.07)

There are few questions about the impact of modern media on family functions. Most of the respondents were either agreed or strongly agreed that the non-users of modern media feel embracement and modern media play important role in changing the norms, value morals, beliefs and ideals of society taught to children. Most of the respondents have a neutral option on the statement that modern media and advancement make life easier by connecting you with all people around the world.

Table 5: Association between use of modern media and family functions

\begin{tabular}{|c|c|c|c|c|c|c|}
\hline & \multicolumn{5}{|c|}{ Change family functions } & \multirow[b]{2}{*}{ Total } \\
\hline Use of modern media & $\begin{array}{l}\text { Strongly } \\
\text { Disagree }\end{array}$ & Disagree & Neutral & Agree & $\begin{array}{l}\text { Strongly } \\
\text { Agree }\end{array}$ & \\
\hline \multirow[t]{2}{*}{ Yes } & 39 & 98 & 117 & 213 & 57 & 524 \\
\hline & $54.17 \%$ & $69.50 \%$ & $89.31 \%$ & $85.20 \%$ & $73.08 \%$ & $77.98 \%$ \\
\hline \multirow[t]{4}{*}{ No } & 33 & 43 & 14 & 37 & 21 & 148 \\
\hline & $45.83 \%$ & $30.50 \%$ & $10.69 \%$ & $14.80 \%$ & $26.92 \%$ & $22.02 \%$ \\
\hline & 72 & 141 & 131 & 250 & 78 & 672 \\
\hline & $100.00 \%$ & $100.00 \%$ & $100.00 \%$ & $100.00 \%$ & $100.00 \%$ & $100.00 \%$ \\
\hline
\end{tabular}

Table 5 reflects the association between the use of modern media and family functions. The calculated values of the Chi-Square (9.64) and Gamma value (0.074) shows the association between both of the variables used in the hypothesis. So the research hypothesis "More use of modern media will decrease the performance of family functions" is proved. The use of modern media effects the relationship of family members and family functions, because the users of these technologies have less quality time to spend with their family members, and their role in family functions is also restricted due to this behavior. The core cause of intimacy between parents and children is based upon the characteristics of family and the intensity of interaction. He critically evaluated that the high frequency of internet utilization by teenagers reduces family interaction time and increases family conflict. Due to maximum use of modern media, family functions have changed. The probability of a family member's cooperation has also decreased.

\section{CONCLUSION}

The results of the current study figured that the excessive usages of modern technologies casted negative impact on family functions. The most dangerous impact was the immoderate usage of modern media technologies, which has decreased the quality and quantity of the time spent with family members. It was observed that there is increasing trends of personal TV sets in bedrooms, mobile phones instead of landline telephone sets, along with the availability of internet at homes. Continuous and maximum usage of modern media decreased the frequency, duration and intensity of interaction among the family members, and increase isolation and depression. To limit the use of modern media, parents should encourage children to increase face to face interaction, outdoor activities and exercises.

\section{RECOMMENDATIONS}

Regarding the significant contribution of the studies, the researcher made some recommendations based on empirical evidence. Because modern media is rapidly devaluing traditional family functions; therefore, there is a special need to filter the positive and negative impact of media to protect traditional family values and their functions. Non-material culture is also being influenced by modern media. People are becoming more individualistic, focusing on themselves rather than their groups. As a result, the joint family system that strengthens the family functions must be encouraged.

\section{REFERENCES}

Ahmad, A. (2016, March 13). Print Media vs. Electronic Media. Retrieved from: http://www.academia .edu/4619886/Print_Media_vs._Electronic_Media. 
Alderfer, M.A., Fiese, B.H., Gold, J.I., Cutuli, J.J., Holmbeck, G.N., Goldbeck, L., Chambers, C.T., Abad, M., Spetter, D., \& Patterson, J. (2008). Evidence-based assessment in pediatric psychology: family measures. Journal of pediatric psychology, 33(9), 1046-1064.

Beavers, R., \& Hampson, R. (2017). The Beavers Systems Model of Family Functioning. The Association for Family Therapy, 22, 128-143.

Church, K., Jenny. (2010). The practice of social research. Wadsworth.

Berkowsky, R.W. (2013). When you cannot get away: Exploring the use of information and communication technologies in facilitating negative work/home spillover. Information \& Communication Society, 16, 519-541.

Buckingham, D. (2000). After the death of the Childhood: Growing Up in the Age of Electronic Media. Blackwell Publishing Limited.

Church, K., Jenny, W., Marsha, B., \& MacDonald, H. (2010). At Home with Media Technology. Journal of Home Cultures, 7(3), 263-286.

Cloninger, J., \& Strembicki, R. (2013). How is technology affecting your family? Retrived from: http://www.huffingtonpost.com/jan-cloninger-and-rosemarystrembicki-lcsw/how-is-technologyaffecting-your-family_b_3915849.html

Creswell, J. (2003). Research design: qualitative, quantities' and mixed methods. Thousand oaks, California sage publication, 12, 214-221

Jenkins, R.H., Shen, C., Dumontheil, I., Thomas, M. S., Elliott, P., Röösli, M., \& Toledano, M. (2020). Social networking site use in young adolescents: Association with health-related quality of life and behavioural difficulties. Computers in Human Behavior, 109, 1-10.

McBurney, D.H, \& White, T.L. (2012). Research Methods (Ed.9 th $^{\text {t }}$. Retrived from: https://www.statisticshowto.datasciencecentral.com/multistage-sampling/.

Mesch, G.S. (2003). The family and the internet: The Israeli case. Social Science Quarterly, 84, 10381050.

Miller, I.W., Ryan, C.E., Keitner, G.I., Bishop, D.S., \& Epstein. N.B. (2000). The McMaster approach to families: Theory, assessment, treatment and research. Journal of Family Therapy, 22, 168-189.

Moradi, T. (2016, April). How has technology affected your life. Retrieved from: http://www.academia.edu/47078 78/How_Has_Technology_Affected_Your_Life

Nachmias, C.F., \& Nachmias, D. (1996). "Research Methods in Social Sciences. Arnold.

Ortiz-Ospina, E. (2019). The rise of modern media. Our World in Data. Retrieved from: https://ourworldindata.org/rise-of-social-media.

Plowman, L., McPake, J., \& Stephen, C. (2008). Just Picking It Up? Young Children Learning with Technology at Home. Cambridge Journal of Education, 38(3), 303- 319.

Plowman, L., McPake, J., \& Stephen, C. (2010). The Technologisation of Childhood? Young Children and Technology in the Home. Journal of Children \& Society, 24(1), 63-74.

Ray, P., \& Spencer, L. (2004). "Personal communication: Not Simply Family of 'Fate' or 'Choice.' Current Sociology, 52, 199-221.

Shahzad, M., Shahzad, M.N., Fatima, S., Hussain S., \& Ahmed, T. (2015). Impact of modernization and changing traditional values of rural setup in District Khushab, The Explorer Islamabad. Journal of Social Science, 1, 394-397.

Sternberg. (2001). A capsule history of theory and research on styles. In R. J. Sternberg, \& L. Zhang (Eds.), Perspectives on thinking, learning and cognitive styles (pp. 1-21). Lawrence Erlbaum Associates, Publishers.

Stevenson, O. (2011). From public policy to family practices: Researching the everyday realities of families' technology use at home. Journal of Computer Assisted Learning, 27, 336-346.

Taft, J. (2015). How does family technology use affect family closeness? Retrieved from: https://blogs.cornell. edu/sharesome/2015/07/16/how-does-family-technology-use-affect-familycohesion/

Todd, E. (2011) L'origine des systèmes familiaux: I. L'Eurasie. Gallimard.

Williams, A.L., \& Merten, M.J. (2011). Family: Internet and social media techno the family context. Family and Consumer Sciences Research journal, 40, 50-170. 